\title{
Levels of cerebrospinal fluid a-synuclein oligomers are increased in Parkinson's disease with dementia and dementia with Lewy bodies compared to Alzheimer's disease
}

\author{
Oskar Hansson ${ }^{1,2^{* \dagger}}$, Sara Hall ${ }^{1,3^{* \dagger}}$, Annika Öhrfelt ${ }^{4}$, Henrik Zetterberg ${ }^{4}$, Kaj Blennow $^{4}$, Lennart Minthon ${ }^{1}$, Katarina Nägga ${ }^{1}$,
} Elisabet Londos ${ }^{1}$, Shiji Varghese ${ }^{5}$, Nour K Majbour ${ }^{5}$, Abdulmonem Al-Hayani ${ }^{6}$ and Omar MA El-Agnaf, ${ }^{5,7^{*}}$

\begin{abstract}
Introduction: The objective was to study whether a-synuclein oligomers are altered in the cerebrospinal fluid (CSF) of patients with dementia, including Parkinson disease with dementia (PDD), dementia with Lewy bodies (DLB), and Alzheimer disease (AD), compared with age-matched controls.

Methods: In total, 247 CSF samples were assessed in this study, including 71 patients with DLB, 30 patients with PDD, 48 patients with AD, and 98 healthy age-matched controls. Both total and oligomeric a-synuclein levels were evaluated by using well-established immunoassays.

Results: The levels of a-synuclein oligomers in the CSF were increased in patients with PDD compared with the controls $(P<0.05)$, but not in patients with DLB compared with controls. Interestingly, the levels of a-synuclein oligomers in the CSF were also significantly higher in patients with PDD $(P<0.01)$ and DLB $(P<0.05)$ compared with patients with AD. The levels of CSF a-synuclein oligomers and the ratio of oligomeric/total-a-synuclein could distinguish DLB or PDD patients from AD patients, with areas under the curves (AUCs) of 0.64 and 0.75 , respectively. In addition, total-a-synuclein alone could distinguish DLB or PDD patients from AD patients, with an AUC of 0.80.
\end{abstract}

Conclusions: The levels of a-synuclein oligomers were increased in the CSF from a-synucleinopathy patients with dementia compared with AD cases.

\section{Introduction}

Alzheimer disease (AD) is the most common form of dementia, and with an increasingly aged population, $\mathrm{AD}$ is predicted to increase worldwide, causing suffering for the patients and their families and a large cost for society [1-3]. Other relatively common neurodegenerative disorders that cause dementia are dementia with Lewy bodies (DLB) and Parkinson disease with dementia (PDD). The symptoms and neuropathologies of these dementia disorders overlap to some extent. AD is characterized by the

\footnotetext{
* Correspondence: oskar.hansson@med.lu.se; sara.hall@med.lu.se; o.elagnaf@uaeu.ac.ae

${ }^{\dagger}$ Equal contributors

'Department of Clinical Sciences, Lund University, Lund, Sweden ${ }^{5}$ Department of Biochemistry, College of Medicine and Health Sciences, United Arab Emirates University, Al Ain, United Arab Emirates Full list of author information is available at the end of the article
}

accumulation of intraneuronal depositions of hyperphosphorylated tau (neurofibrillary tangles) and extracellular aggregates of $\beta$-amyloid (amyloid plaques) [3]. DLB and PDD, however, are $\alpha$-synucleinopathies that are characterized by intraneuronal aggregates consisting mainly of $\alpha$-synuclein fibrils, which are found in Lewy bodies (LBs) and Lewy neuritis [4]. However, amyloid accumulation often also occurs in patients with DLB, and an AD-like pathology can also be found in patients with PDD. In addition, many AD cases also develop LBs [5,6].

The oligomerization of $\beta$-amyloid and $\alpha$-synuclein appear to be key events in the pathology of AD and DLB/ PDD, respectively [4]. Currently, several ongoing studies are addressing potential disease-modifying treatments that are directed against pathology-specific mechanisms, such as the aggregation and formation of the neurotoxic

\section{() Biomed Central}


oligomeric species of $\beta$-amyloid or $\alpha$-synuclein [7]. Biomarkers that can determine which brain pathologies underlie the symptoms of an individual patient, instead of classifying patients according to clinical syndromes, will be very helpful when selecting patients with early symptoms for new clinical trials to evaluate new diseasemodifying therapies.

Biomarkers are available to aid in the diagnosis of $\mathrm{AD}$, and several studies have shown that $\beta$-amyloid1-42 (A $\beta 1-42)$ level is decreased and that the total tau ( $t$-tau) and phosphorylated tau ( $\mathrm{p}$-tau) levels are increased in the cerebrospinal fluid (CSF) of patients with AD compared with cognitively healthy controls [8-11].

Some studies have shown that the total levels of $\alpha$ synuclein in the CSF are significantly decreased in patients with PD or DLB compared with patients with AD [12-14], but other groups have reported conflicting results [15-17]. During recent years, it has become increasingly evident that early aggregates or "soluble oligomers" of $\alpha$-synuclein play an important role in the pathogenesis of $\alpha$-synucleinopathies rather than the late aggregates or "amyloid fibrils." Thus, high levels of soluble $\alpha$-synuclein oligomers are present in the brain homogenates of patients with PD and DLB $[18,19]$. More recent studies have shown that the oligomeric forms of $\alpha$-synuclein are neurotoxic in vitro and in vivo [20-23]. We and others recently reported elevated levels of $\alpha$-synuclein oligomers and an increased oligomer/total- $\alpha$-synuclein ratio in the CSF of PD patients compared with controls $[24,25]$. These findings suggested that CSF $\alpha$-synuclein oligomers could be useful biomarkers for the diagnosis and early detection of PD [24,25].

We studied the levels of CSF $\alpha$-synuclein oligomers in dementia cases with LBs compared with the levels in dementia cases with AD and in healthy elderly controls.

\section{Methods \\ Study participants}

In the present study, we included 247 CSF samples from subjects with $\mathrm{AD}(n=48), \operatorname{PDD}(n=30)$, and DLB $(n=71)$ and from nondemented elderly controls $(n=98)$ at the Memory Clinic, Skåne University Hospital, Sweden. All patients underwent brain imaging; routine laboratory testing; and detailed neurologic, psychiatric and cognitive examinations by a medical doctor experienced in dementia disorders. Patients diagnosed with PDD met the Clinical Diagnostic Criteria for Dementia Associated with PD according to Emre et al. [26]. Patients who received an AD diagnosis met the DSM-IIIR criteria for dementia [27]. The criteria for probable AD were defined by NINCDS-ADRDA [28]. Patients with DLB met the consensus criteria according to McKeith et al. [29]. All controls underwent cognitive testing and neurologic examination by a medical doctor, and individuals with objective cognitive or parkinsonian symptoms were not included as controls in the present study.

All individuals gave informed consent either by use of a passive-consent procedure in which consent for the retrospective use of banked clinical samples and data was assumed if individuals did not actively retract permission, as instructed in local press advertisements, or by active written informed consent. This study procedure was approved by the local ethics committee at Lund University Sweden and conducted according to the Helsinki Declaration.

\section{CSF samples}

The CSF samples were obtained by lumbar puncture in the L3/L4 or L4/L5 interspace in the morning from nonfasted patients. The samples were collected in polypropylene tubes and gently mixed to avoid gradient effects. All samples were centrifuged within 30 minutes at $4^{\circ} \mathrm{C}$ at $2,000 \mathrm{~g}$ for 10 minutes to remove the cells and debris and then stored in aliquots at $-80^{\circ} \mathrm{C}$ until the biochemical analysis.

\section{Immunoassay for measuring oligomeric a-synuclein in the CSF}

A 384-well ELISA microplate was coated by overnight incubation at $4^{\circ} \mathrm{C}$ with $1 \mu \mathrm{g} / \mathrm{ml} \mathrm{mAb} 211$ (Santa Cruz Biotechnology, USA) in $200 \mathrm{mM} \mathrm{NaHCO} 3, \mathrm{pH} 9.6$ (50 $\mu \mathrm{l} /$ well). The plate was washed with phosphate-buffered saline (PBS) containing 0.05\% Tween-20 (PBST) and incubated with $100 \mu \mathrm{l} /$ well of blocking buffer (PBS containing $2.5 \%$ gelatin and $0.05 \%$ Tween-20) for 2 hours at $37^{\circ} \mathrm{C}$. After washing, $50 \mu \mathrm{l}$ of the CSF samples (thawed on ice before Tween-20 was added to a final concentration of $0.05 \%)$ was added to each well, and then the plate was incubated at $37^{\circ} \mathrm{C}$ for another 3 hours. Biotinylated 211 diluted to $1 \mu \mathrm{g} / \mathrm{ml}$ in blocking buffer was added, and the plate was incubated at $37^{\circ} \mathrm{C}$ for 2 hours. The plate was washed and then incubated for 1 hour at $37^{\circ} \mathrm{C}$ with $50 \mu \mathrm{l} /$ well of ExtrAvidin-Peroxidase (Sigma-Aldrich, Dorset, UK). After washing, the plate was incubated with $50 \mu \mathrm{l} /$ well of an enhanced chemiluminescent substrate (SuperSignal ELISA Femto; Pierce Biotechnology, Rockford, IL, USA). Then the chemiluminescence in relative light units was immediately measured with a Victor ${ }^{3} 1420$ (Wallac) microplate reader [30,31]. The samples were screened in a blind fashion and tested randomly. The case and control samples were run on a single plate to avoid plate-to-plate variations, and the results were confirmed with at least two independent experiments.

\section{Analysis of total levels of a-synuclein in CSF samples}

The levels of total $\alpha$-synuclein were quantified by using a newly developed bead-based xMAP technology assay, and these results were included in a previous report [14]. In 
brief, a monoclonal antibody (MAb), 9B6 IgG1, which recognizes a human-specific $\alpha$-synuclein $\mathrm{C}$-terminal epitope in exon 5, was used as the capture antibody. The antibody was covalently coupled to carboxylated beads (region 126). The MAb 4D8 IgG1, an antibody recognizing an $\mathrm{N}$-terminal epitope in exon 3 of $\alpha$-synuclein, was used as the detector in its biotinylated form. The bead assay was combined with bead-controlling heterophilic antibody interference (a specific MAb, bead 150) [32]. Heterophilic antibodies are a common problem in immunoassays [33] and have been used to exclude samples in plasma studies [34]. Although the problem of heterophilic antibodies has also been acknowledged in CSF studies [35], heterophilic antibodies were not observed in any of the 247 CSF samples analyzed herein, by using an arbitrary cut-off of an MFI of 150 . The assays were analyzed on a Luminex 100IS instrument.

\section{Statistical analysis}

The statistical analyses were conducted with SPSS for Windows, version 20.0 (SPSS Inc., Chicago, IL, USA). The correlation analyses were performed by using the Spearman rank correlation test $\left(R_{s}\right)$. To compare the demographic and CSF baseline data between groups, the Mann-Whitney $U$ test was used for continuous variables, and the Pearson $\chi^{2}$ test was used for dichotomous variables.

\section{Results}

The levels of oligomeric and total a-synuclein in the CSF samples

Both total and oligomeric forms of $\alpha$-synuclein were assessed in the CSF samples from 71 DLB patients, 30 PDD patients, $48 \mathrm{AD}$ patients, and 98 healthy elderly controls. The demographic data are presented in Table 1.
The levels of $\alpha$-synuclein oligomers in the CSF were increased in patients with PDD compared with the controls $(P<0.05$; see Table 1 and Figure 1$)$, but not in patients with DLB compared with controls. Interestingly, the CSF levels of the $\alpha$-synuclein oligomers were also higher in both the PDD and DLB patients compared with the AD cases $(P<0.01$ and $P<0.05$, respectively; see Table 1 and Figure 1A). Similarly, the ratio of $\alpha$-synuclein oligomers/ total- $\alpha$-synuclein was also elevated in patients with PDD and DLB compared with the ratio in patients with $\mathrm{AD}$ $(P<0.01$; see Table 1 and Figure 1B).

Diagnostic accuracy of the oligomeric and total a-synuclein Both CSF $\alpha$-synuclein oligomers levels and the $\alpha$-synuclein oligomers/total- $\alpha$-synuclein ratio could distinguish DLB and PDD patients from AD patients, with AUCs of 0.64 and 0.75 , respectively. However, in this cohort, the diagnostic accuracy of the CSF total $\alpha$-synuclein levels was even higher, with an AUC of 0.80 (Figure 2).

\section{Associations between oligomeric a-synuclein and cognitive performance}

No significant correlations were found between the CSF $\alpha$-synuclein oligomers levels and the cognitive performance, as measured with the MMSE in the PDD patients, DLB patients, and healthy controls. However, in the AD cases, increased levels of $\alpha$-synuclein oligomers in the CSF correlated with worse performance on the MMSE $\left(\mathrm{R}_{\mathrm{s}}=-0.31 ; P<0.05\right)$.

No correlations appeared between the CSF $\alpha$-synuclein oligomers and either age, gender, or disease duration (data not shown).

\section{Discussion}

The discovery of missense and multiplication mutations in $S N C A$ that were linked to clinical and pathologic

Table 1 Demographic data and the levels of total and oligomeric a-synuclein and the oligomer/t-a-synuclein ratio in the CSF

\begin{tabular}{|c|c|c|c|c|}
\hline & Controls & PDD & DLB & $A D$ \\
\hline Number & 98 & 30 & 71 & 48 \\
\hline Male/Female & $35 / 63$ & $22 / 8^{a}$ & $49 / 22^{a}$ & $13 / 35^{c, d}$ \\
\hline Age, years & 69 (11.6) & $76(5.5)^{a}$ & $74(7.4)^{b}$ & $77(5.6)^{a, e}$ \\
\hline MMSE & $29(28-30)$ & $23.5(17-25)^{a}$ & $21(17-24.75)^{a}$ & $21(19-23)^{a}$ \\
\hline a-Synuclein oligomers & $37,882(21,763-136,685)$ & $73,309(36,361-326,297)^{b}$ & $40,440(22,235-137,845)$ & $26,441(21,548-44,332)^{b, c, ~ e ~}$ \\
\hline $\begin{array}{l}\text { a-Synuclein oligomers/ } \\
\text { a-Synuclein total }\end{array}$ & 549 (372-2149) & $1,333(492-5,973)^{b}$ & $811(379-2,238)$ & $333(199-718)^{a, c, d}$ \\
\hline a-Synuclein total & $67.00(52.00-86.00)$ & $61.50(51.25-68.25)$ & $58.00(43.75-75.00)$ & $94.00(76.00-121.00)^{a, c, d}$ \\
\hline
\end{tabular}

The data are presented as the median (25th to 75th percentile), except for age, where the data were normally distributed. The data for age are presented as the mean (SD). The a-synuclein oligomer levels are presented in RLU. The total a-synuclein levels are presented in ng/L. For a-synuclein total and a-synuclein oligomers/a-synuclein total, only CSF samples with hemoglobin less than $1,000 \mathrm{ng} / \mathrm{L}$ were included.

${ }^{\mathrm{a}, \mathrm{b}}$ Compared with the controls, ${ }^{\mathrm{a}} P<0.001,{ }^{\mathrm{b}} P<0.05$.

${ }^{\mathrm{c}}$ Compared with PDD patients, ${ }^{\mathrm{C}} P<0.001$.

d, e Compared with DLB patients, ${ }^{d} P<0.001,{ }^{e} P<0.05$. 



Figure 1 Levels of $a$-synuclein oligomers ( $A$; RLU, relative luminescence units) and the ratio of a-synuclein oligomers to total-a-synuclein (B; oligomer/total ratio, \%) in the CSF of healthy elderly individuals $(n=98)$ and of patients with PDD $(n=30)$, DLB $(n=71)$ or AD $(n=48)$. The levels of a-synuclein oligomers and the ratio were increased in patients with PDD compared with patients with $A D$ and healthy controls (Mann-Whitney $U$ test; $P<0.05)$. The box represents the interquartile range $(I Q R)$, with the median indicated in the middle. The error bars represent the lowest and highest normal values (max 1.5 box lengths from the lower and upper quartiles, respectively).

phenotypes ranging from PD to PDD and DLB [36-39] highlighted the direct role of $\alpha$-synuclein overexpression in the pathogenesis of these disorders. Furthermore, abnormal aggregates of $\alpha$-synuclein protein were identified as the main components of LBs, the pathologic hallmark of PD, PDD, and DLB [40]. Therefore, $\alpha$-synuclein misfolding and aggregation in the brain are considered pivotal factors in the degeneration process. Early aggregates or "soluble oligomers" of $\alpha$-synuclein may be the pathogenic species that lead to neuronal death and neurodegeneration, rather than the late aggregates "amyloid fibrils" [21,22]. High levels of $\alpha$-synuclein oligomers are present in brain homogenates from patients with

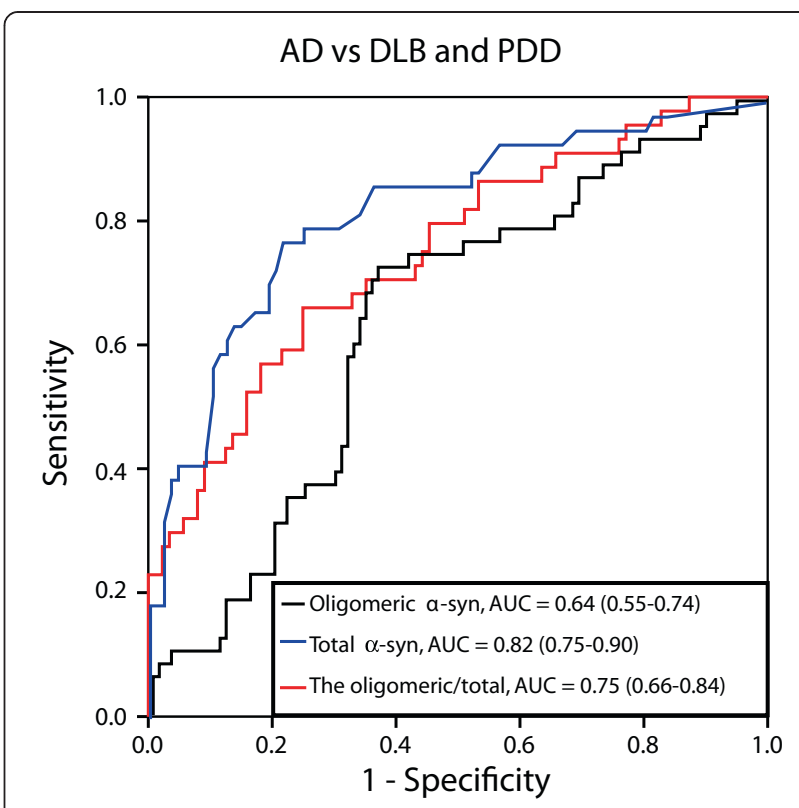

Figure 2 Receiver operating characteristic curves (ROC) showing the diagnostic accuracy of a-synuclein oligomers levels (black), the ratio of $a$-synuclein oligomers/total-a-synuclein (red) and total- $a$-synuclein levels (blue) when differentiating patients with DLB and PDD from patients with AD.

PD and DLB compared with normal brains $[18,19]$. Interestingly, we and others previously reported significant differences between the CSF $\alpha$-synuclein oligomers in PD patients compared with age-matched controls, with most of the PD samples showing higher levels of CSF $\alpha$-synuclein oligomers than did age-matched controls [24,25]. The aim of this study was to determine whether $\alpha$-synuclein oligomers levels and $\alpha$-synuclein oligomers/ total- $\alpha$-synuclein ratio in the CSF are elevated in $\alpha$ synucleinopathies cases with dementia compared with $\mathrm{AD}$ patients and elderly healthy controls. In the present study, we reported CSF levels of the oligomeric $\alpha$-synuclein in PDD, DLB, and AD cases. Interestingly, we observed high levels of CSF $\alpha$-synuclein oligomers and high $\alpha$-synuclein oligomers/total- $\alpha$-synuclein ratio in PDD and DLB, which was evident when compared with CSF samples from patients with AD (Figure 1). We found no associations between the CSF levels of the oligomeric $\alpha$-synuclein and cognitive performance in patients with PDD or DLB.

In contrast, $\mathrm{AD}$ patients with higher levels of CSF $\alpha$-synuclein oligomers exhibited a worse cognitive performance, although the correlation was very weak, indicating that $\mathrm{AD}$ patients with LB pathology could develop more severe dementia.

Currently, distinguishing dementia patients with AD from those patients with DLB relies on a clinical history and examination. However, to design a better treatment plan, objective methods to discriminate $\mathrm{AD}$ cases from DLB cases are needed. For example, the neuroleptic 
drugs that are often used to treat the psychiatric symptoms in AD can be detrimental to DLB patients. Because of the overlapping pathologies between these two disorders, the standard CSF biomarkers for AD $\left(\mathrm{A} \beta_{1-42}\right.$, $\mathrm{T}$-tau, and P-tau) do not readily discriminate between them [41-44]. Future large clinical studies are needed to evaluate whether CSF $\alpha$-synuclein oligomers, when combined with biomarkers for AD, could increase the diagnostic precision in distinguishing dementia patients with AD from those patients with DLB and PDD.

We believe that the $\alpha$-synuclein oligomers detected in CSF are derived from the neurons of the central nervous system. Therefore, the concentration of the oligomeric forms of $\alpha$-synuclein in the CSF would correlate with the levels of soluble $\alpha$-synuclein aggregates that are present in the brain. To address this issue, CSF studies with neuropathologic outcomes are needed. CSF $\alpha$-synuclein oligomers might, however, serve as markers for selecting the correct patient population for clinical trials that are designed to evaluate new experimental therapies targeting $\alpha$-synuclein oligomers in the brain. Selected patients with high levels of CSF $\alpha$-synuclein oligomers could be more likely to respond to such therapies [7]. Moreover, the quantification of the levels of CSF $\alpha$ synuclein oligomers at the baseline and during the treatment would assist with the identification of the most promising and effective drug candidates and doses in large-scale clinical trials.

\section{Conclusions}

In summary, our results demonstrated that the levels of $\alpha$-synuclein oligomers and oligomers/total- $\alpha$-synuclein ratio in the CSF are increased in patients with dementia and LBs pathology. However, our findings need further validation by independent studies in independent cohorts with neuropathlogical outcome data.

\section{Abbreviations \\ AD: Alzheimer disease; CSF: cerebrospinal fluid; DLB: dementia with Lewy bodies; LBs: Lewy bodies; PDD: Parkinson disease with dementia; p-tau: phosphorylated tau; t-tau: total tau.}

\section{Competing interests}

The authors declare that they have no competing interests.

\begin{abstract}
Authors' contributions
$\mathrm{OH}, \mathrm{SH}$, and $\mathrm{OE}$ performed the study design, interpretation of the results, and writing of the manuscript draft. $A O, H Z, K B, L M, K N, E L, A H, S V$, and NM contributed to the study concept and design, and to critical revision of the manuscript for important intellectual content. $H Z, K B, L M, K N$, and EL collected data and contributed to interpretation of results. SV and NM performed the experiments and analyzed and compiled data. $\mathrm{OH}$ and $\mathrm{OE}$ performed the study supervision. All authors read and approved the final manuscript.
\end{abstract}

\section{Acknowledgements}

This work was supported by grant from The Alzheimer's Drug Discovery Foundation and the Lewy Body Dementia Association, the Swedish Research Council; and The Regional Agreement on Medical Training and Clinical Research (ALF) between Skåne County Council and Lund University and between the Sahlgrenska University Hospital and the Sahlgrenska Academy. The funding sources had no role in the design and conduct of the study; in the collection, analysis, and interpretation of the data; or in the preparation, review, or approval of the manuscript.

\section{Author details}

${ }^{1}$ Department of Clinical Sciences, Lund University, Lund, Sweden. ${ }^{2}$ Memory clinic, Skåne University Hospital, Lund, Sweden. ${ }^{3}$ Neurology clinic, Skåne

University Hospital, Lund, Sweden. ${ }^{4}$ Institute of Neuroscience and Physiology, Department of Psychiatry and Neurochemistry, The Sahlgrenska Academy at University of Gothenburg, Gothenburg, Sweden. ${ }^{5}$ Department of

Biochemistry, College of Medicine and Health Sciences, United Arab Emirates University, Al Ain, United Arab Emirates. ${ }^{6}$ Department of Anatomy, Faculty of Medicine, King Abdulaziz University, Jeddah, Saudi Arabia. ${ }^{7}$ Faculty of

Medicine, King Abdulaziz University, Jeddah, Saudi Arabia.

Received: 11 January 2014 Accepted: 8 April 2014

Published: 7 May 2014

\section{References}

1. Ferri CP, Prince M, Brayne C, Brodaty H, Fratiglioni L, Ganguli M, Hall K, Hasegawa K, Hendrie H, Huang Y, Jorm A, Mathers C, Menezes PR, Rimmer E, Scazufca M, International AD: Global prevalence of dementia: a Delphi consensus study. Lancet 2005, 366:2112-2117.

2. Blennow K, de Leon MJ, Zetterberg H: Alzheimer's disease. Lancet 2006, 368:387-403.

3. Ballard C, Gauthier S, Corbett A, Brayne C, Aarsland D, Jones E: Alzheimer's disease. Lancet 2011, 377:1019-1031.

4. Eller M, Williams DR: alpha-Synuclein in Parkinson disease and other neurodegenerative disorders. Clin Chem Lab Med 2011, 49:403-408.

5. Caballol N, Marti MJ, Tolosa E: Cognitive dysfunction and dementia in Parkinson disease. Mov Disord 2007, 22:S358-S366.

6. Compta Y, Parkkinen L, O'Sullivan SS, Vandrovcova J, Holton JL, Collins C, Lashley T, Kallis C, Williams DR, de Silva R, Lees AJ, Revesz T: Lewy- and Alzheimer-type pathologies in Parkinson's disease dementia: which is more important? Brain 2011, 134:1493-1505.

7. Hampel H, Frank R, Broich K, Teipel SJ, Katz RG, Hardy J, Herholz K, Bokde AL, Jessen F, Hoessler YC, Sanhai WR, Zetterberg H, Woodcock J, Blennow K: Biomarkers for Alzheimer's disease: academic, industry and regulatory perspectives. Nat Rev Drug Discov 2010, 9:560-574.

8. Blennow K, Hampel H, Weiner M, Zetterberg H: Cerebrospinal fluid and plasma biomarkers in Alzheimer disease. Nat Rev Neurol 2010, 6:131-144.

9. Perrin RJ, Fagan AM, Holtzman DM: Multimodal techniques for diagnosis and prognosis of Alzheimer's disease. Nature 2009, 461:916-922.

10. Shaw LM, Vanderstichele H, Knapik-Czajka M, Clark CM, Aisen PS, Petersen RC, Blennow K, Soares H, Simon A, Lewczuk P, Dean R, Siemers E, Potter W, Lee VM, Trojanowski JQ, Initiative ADN: Cerebrospinal fluid biomarker signature in Alzheimer's disease neuroimaging initiative subjects. Ann Neurol 2009, 65:403-413.

11. Hansson O, Zetterberg H, Buchhave P, Londos E, Blennow K, Minthon L: Association between CSF biomarkers and incipient Alzheimer's disease in patients with mild cognitive impairment: a follow-up study. Lancet Neurol 2006, 5:228-234.

12. Shi M, Bradner J, Hancock AM, Chung KA, Quinn JF, Peskind ER, Galasko D, Jankovic J, Zabetian CP, Kim HM, Leverenz JB, Montine TJ, Ginghina C, Kang UJ, Cain KC, Wang Y, Aasly J, Goldstein D, Zhang J: Cerebrospinal fluid biomarkers for Parkinson disease diagnosis and progression. Ann Neurol 2011, 69:570-580.

13. Kasuga K, Tokutake T, Ishikawa A, Uchiyama T, Tokuda T, Onodera O Nishizawa M, Ikeuchi T: Differential levels of alpha-synuclein, betaamyloid42 and tau in CSF between patients with dementia with Lewy bodies and Alzheimer's disease. J Neurol Neurosurg Psychiatry 2010, 81:608-610.

14. Hall S, Ohrfelt A, Constantinescu R, Andreasson U, Surova $Y$, Bostrom F, Nilsson C, Widner H, Decraemer H, Nagga K, Minthon L, Londos E, Vanmechelen E, Holmberg B, Zetterberg H, Blennow K, Hansson O: Accuracy of a panel of 5 cerebrospinal fluid biomarkers in the differential diagnosis of patients with dementia and/or parkinsonian disorders. Arch Neurol 2012, 1-8. 
15. Spies PE, Melis RJ, Sjogren MJ, Rikkert MG, Verbeek MM: Cerebrospinal fluid alpha-synuclein does not discriminate between dementia disorders. J Alzheimers Dis 2009, 16:363-369.

16. Reesink FE, Lemstra AW, van Dijk KD, Berendse HW, van de Berg WD, Klein M, Blankenstein MA, Scheltens P, Verbeek MM, van der Flier WM: CSF alpha-synuclein does not discriminate dementia with Lewy bodies from Alzheimer's disease. J Alzheimers Dis 2010, 22:87-95.

17. Noguchi-Shinohara M, Okuda T, Yoshita M, Kasai T, Ono K, Nakagawa M, El-Agnaf OM, Yamada M: CSF alpha-synuclein levels in dementia with Lewy bodies and Alzheimer's disease. Brain Res 2009, 1251:1-6.

18. Paleologou KE, Kragh CL, Mann DM, Salem SA, Al-Shami R, Allsop D, Hassan $\mathrm{AH}$, Jensen $\mathrm{PH}$, El-Agnaf OM: Detection of elevated levels of soluble alpha-synuclein oligomers in post-mortem brain extracts from patients with dementia with Lewy bodies. Brain 2009, 132:1093-1101.

19. Sharon R, Bar-Joseph I, Frosch MP, Walsh DM, Hamilton JA, Selkoe DJ: The formation of highly soluble oligomers of alpha-synuclein is regulated by fatty acids and enhanced in Parkinson's disease. Neuron 2003, 37:583-595.

20. Winner B, Jappelli R, Maji SK, Desplats PA, Boyer L, Aigner S, Hetzer C, Loher T, Vilar M, Campioni S, Tzitzilonis C, Soragni A, Jessberger S, Mira H, Consiglio A, Pham E, Masliah E, Gage FH, Riek R: In vivo demonstration that alpha-synuclein oligomers are toxic. Proc Natl Acad Sci U S A 2011, 108:4194-4199.

21. Brown DR: Oligomeric alpha-synuclein and its role in neuronal death. IUBMB Life 2010, 62:334-339.

22. Vekrellis K, Vekrellis K, Xilouri M, Emmanouilidou E, Rideout HJ, Stefanis L: Pathological roles of alpha-synuclein in neurological disorders. Lancet Neurol 2011, 10:1015-1025.

23. Sulzer D: Clues to how alpha-synuclein damages neurons in Parkinson's disease. Mov Disord 2010, 25:S27-S31.

24. Park MJ, Cheon SM, Bae HR, Kim SH, Kim JW: Elevated levels of alpha-synuclein oligomer in the cerebrospinal fluid of drug-naive patients with Parkinson's disease. J Clin Neurol 2011, 7:215-222.

25. Tokuda T, Tokuda T, Qureshi MM, Ardah MT, Varghese S, Shehab SA, Kasai T, Ishigami N, Tamaoka A, Nakagawa M, El-Agnaf OM: Detection of elevated levels of alpha-synuclein oligomers in CSF from patients with Parkinson disease. Neurology 2010, 75:1766-1772.

26. Emre M, Aarsland D, Brown R, Burn DJ, Duyckaerts C, Mizuno Y, Broe GA Cummings J, Dickson DW, Gauthier S, Goldman J, Goetz C, Korczyn A, Lees A, Levy R, Litvan I, McKeith I, Olanow W, Poewe W, Quinn N, Sampaio C, Tolosa E, Dubois B: Clinical diagnostic criteria for dementia associated with Parkinson's disease. Mov Disord 2007, 22:1689-1707. quiz 1837.

27. American Psychiatric Association, APA: Diagnostic and Statistical Manual of Mental Disorders. Third editionth edition. Washington, DC: 1987:133-155.

28. McKhann G, Drachman D, Folstein M, Katzman R, Price D, Stadlan EM: Clinical diagnosis of Alzheimer's disease: report of the NINCDS-ADRDA Work Group under the auspices of Department of Health and Human Services Task Force on Alzheimer's Disease. Neurology 1984, 34:939-944.

29. McKeith IG, Dickson DW, Lowe J, Emre M, O'Brien JT, Feldman H, Cummings J, Duda JE, Lippa C, Perry EK, Aarsland D, Arai H, Ballard CG, Boeve B, Burn DJ, Costa D, Del Ser T, Dubois B, Galasko D, Gauthier S, Goetz CG, Gomez-Tortosa E, Halliday G, Hansen LA, Hardy J, Iwatsubo T, Kalaria RN, Kaufer D, Kenny RA, Korczyn A, et al: Diagnosis and management of dementia with Lewy bodies: third report of the DLB Consortium. Neurology 2005, 65:1863-1872.

30. El-Agnaf OM, Salem SA, Paleologou KE, Curran MD, Gibson MJ, Court JA, Schlossmacher MG, Allsop D: Detection of oligomeric forms of alpha-synuclein protein in human plasma as a potential biomarker for Parkinson's disease. FASEB J 2006, 20:419-425.

31. Parnetti $L$, Chiasserini D, Persichetti E, Eusebi P, Varghese S, Qureshi MM, Dardis A, Deganuto M, De Carlo C, Castrioto A, Balducci C, Paciotti S, Tambasco N, Bembi B, Bonanni L, Onofrj M, Rossi A, Beccari T, El-Agnaf O, Calabresi P: Cerebrospinal fluid lysosomal enzymes and a-synuclein in Parkinson's disease. Mov Disord doi:10.1002/mds.25772. [Epub ahead of print]

32. Sehlin D, Hedlund M, Lord A, Englund H, Gellerfors P, Paulie S, Lannfelt L, Pettersson FE: Heavy-chain complementarity-determining regions determine conformation selectivity of anti-abeta antibodies. Neurodegener Dis 2011, 8:117-123

33. Sturgeon CM, Viljoen A: Analytical error and interference in immunoassay: minimizing risk. Ann Clin Biochem 2011, 48:418-432.
34. Hansson $\mathrm{O}$, Zetterberg $\mathrm{H}$, Vanmechelen $\mathrm{E}$, Vanderstichele $\mathrm{H}$, Andreasson $\mathrm{U}$, Londos E, Wallin A, Minthon L, Blennow K: Evaluation of plasma Abeta(40) and Abeta(42) as predictors of conversion to Alzheimer's disease in patients with mild cognitive impairment. Neurobiol Aging 2010, 31:357-367.

35. Sehlin D, Sollvander S, Paulie S, Brundin R, Ingelsson M, Lannfelt L, Pettersson $\mathrm{FE}$, Englund $\mathrm{H}$ : Interference from heterophilic antibodies in amyloid-beta oligomer ELISAs. J Alzheimers Dis 2010, 21:1295-1301.

36. Meeus B, Verstraeten A, Crosiers D, Engelborghs S, Van den Broeck M, Mattheijssens M, Peeters K, Corsmit E, Elinck E, Pickut B, Vandenberghe $R$, Cras P, De Deyn PP, Van Broeckhoven C, Theuns J: LB and PDD: a role for mutations in dementia and Parkinson disease genes? Neurobiol Aging 2012, 33:629. e5-629 e18.

37. Ahn TB, Kim SY, Kim JY, Park SS, Lee DS, Min HJ, Kim YK, Kim SE, Kim JM, Kim HJ, Cho J, Jeon BS: alpha-Synuclein gene duplication is present in sporadic Parkinson disease. Neurology 2008, 70:43-49.

38. Fuchs J, Nilsson C, Kachergus J, Munz M, Larsson EM, Schule B, Langston JW, Middleton FA, Ross OA, Hulihan M, Gasser T, Farrer MJ: Phenotypic variation in a large Swedish pedigree due to SNCA duplication and triplication. Neurology 2007, 68:916-922.

39. Polymeropoulos MH, Lavedan C, Leroy E, Ide SE, Dehejia A, Dutra A, Pike B, Root H, Rubenstein J, Boyer R, Stenroos ES, Chandrasekharappa S, Athanassiadou A, Papapetropoulos T, Johnson WG, Lazzarini AM, Duvoisin RC, Di lorio G, Golbe LI, Nussbaum RL: Mutation in the alpha-synuclein gene identified in families with Parkinson's disease. Science 1997, 276:2045-2047.

40. Baba M, Nakajo S, Tu PH, Tomita T, Nakaya K, Lee VM, Trojanowski JQ, Iwatsubo T: Aggregation of alpha-synuclein in Lewy bodies of sporadic Parkinson's disease and dementia with Lewy bodies. Am J Pathol 1998, 152:879-884.

41. Mollenhauer B, Cepek L, Bibl M, Wiltfang J, Schulz-Schaeffer WJ, Ciesielczyk B, Neumann M, Steinacker P, Kretzschmar HA, Poser S, Trenkwalder C, Otto M: Tau protein, Abeta42 and S-100B protein in cerebrospinal fluid of patients with dementia with Lewy bodies. Dement Geriatr Cogn Disord 2005, 19:164-170.

42. Mollenhauer B, Trenkwalder C, von Ahsen N, Bibl M, Steinacker P, Brechlin P, Schindehuette J, Poser S, Wiltfang J, Otto M: Beta-amlyoid 1-42 and tau-protein in cerebrospinal fluid of patients with Parkinson's disease dementia. Dement Geriatr Cogn Disord 2006, 22:200-208.

43. Andersson $M$, Zetterberg $H$, Minthon $L$, Blennow K, Londos E: The cognitive profile and CSF biomarkers in dementia with Lewy bodies and Parkinson's disease dementia. Int J Geriatr Psychiatry 2010, 26:100-105.

44. Hu WT, Chen-Plotkin A, Arnold SE, Grossman M, Clark CM, Shaw LM, McCluskey L, Elman L, Karlawish J, Hurtig HI, Siderowf A, Lee VM, Soares H, Trojanowski JQ: Biomarker discovery for Alzheimer's disease, frontotemporal lobar degeneration, and Parkinson's disease. Acta Neuropathol 2010, 120:385-399.

\section{doi:10.1186/alzrt255}

Cite this article as: Hansson et al:: Levels of cerebrospinal fluid asynuclein oligomers are increased in Parkinson's disease with dementia and dementia with Lewy bodies compared to Alzheimer's disease. Alzheimer's Research \& Therapy 2014 6:25.

\section{Submit your next manuscript to BioMed Central and take full advantage of:}

- Convenient online submission

- Thorough peer review

- No space constraints or color figure charges

- Immediate publication on acceptance

- Inclusion in PubMed, CAS, Scopus and Google Scholar

- Research which is freely available for redistribution 